\section{ANNUAL VISITATION OF THE ROYAL OBSERVATORY}

Saturday last the Board of Visitors of the Royal Observatory made their annual visitation to our National Observatory to examine into the work done, and to receive the Report of the Astronomer Royal. We have not space for the report in full, but this is not to be regretted, for it contains a quantity of minute detail about trivial matters which the ordinary run of mankind would not think worth the printing.

There are, however, several points of great scientific interest in the Report, the new Water Telescope and the instruments for use in the approaching observations of the Transit of Venus having been the lions at Greenwich.

The correction for level-error in the transit instrument having become inconveniently large, owing apparently to a gradual subsidence of the eastern support since the erection of the instrument, about a ton weight of stone was placed on the western pier. Not the slightest change, however, could be traced as due to this; the level-error maintaining its usual value. This plan having failed, the stones were removed, and a sheet of very thin paper, ${ }_{2}^{T} \frac{T}{7} 0$ inch in thickness, was placed under the eastern $\mathrm{Y}$, which was raised from its bed for the purpose. The collimators having been observed just before this operation, no difficulty was experienced in adjusting the instrument so as to have very nearly the same error of Azimuth as before. The mean annual value of the level-error appears to be now sensibly zero. This will give some idea of the delicate arrangements necessary for this ponderous instrument.

The usual course of Astronomical observations now carried out for so many years has been adhered to. The list of fundamental stars used for determination of clockerror has been increased to 2 Io. Besides these, Nautical Almanac, circumpolar, and moon-culminating stars have been observed; also refraction stars, stars with large proper-motion, and stars which are required for any special investigation. A few of Bradley's stars which had been inadvertently omitted have been observed in the past year. The Sun, Moon, and large planets have been observed as usual. As the siege and war operations in Paris seriously interfered with the observations of small planets made at the Paris Observatory, observations of them were continued at Greenwich throughout each entire lunation during the investment of the city.

The observations of $\gamma$ Draconis, the star which passes very near the Zenith of Greenwich, with the Water Telescope, made in the spring of the present year, are completely reduced, with the exception of a small correction for the positions of the micrometer-wires, to be determined shortly. As the astronomical latitude of the place of observation is not known (it is not many yards from the transit circle), the bearing of these observations on the question of aberration cannot be certainly pronounced until the autumn observations shall have been made; but, supposing the geodetic latitude to be accordant with the astronomical latitude, the result for aberration appears to be sensibly the same as with ordinary telescopes.

With regard to the Magnetic instruments, the Astro. nomer Royal states that a plan was arranged last year for photographic impression of hour-lines upon the photographic sheets carrying the records of the three Magnetometers and of the Earth-current Galvanometers: an arrangement already for some time carried out in the new instruments by Dr. Balfour Stewart. The beam of light, constantly directed through a cylindrical lens to fall upon the sheet, emanates from one of the existing lamps, or (in one instrument), from a flame specially mounted for it ; it is, however, obstructed by a shade till $2 \frac{1}{2}$ minutes before each hour, and acts till $2 \frac{1}{2}$ minutes after each hour. The connections of the shades were so arranged that all could be opened and closed by a single wire.

The following numerical results of the magnetic elements for 1870 may be interesting :-

Mean westerly declination . $19^{\circ} 54^{\prime}$ nearly.

Mean horizontal force . . $\left\{3 \cdot 86_{5}\right.$ (in English units).

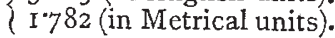

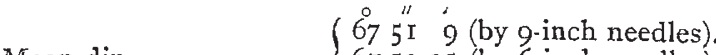
$\{675225$ (by 6 -inch needles). (67534I (by 3 -inch needles).

The observations of dip at different hours appear to show a diminution from 9 h. A.M. to 3 h. P.M.

A small Appendix of great interest is attached to the report. Those who have given attention to the history of Terrestrial Magnetism are aware that Halley's Magnetic Chart is very frequently cited ; but the Astronomer Royal could not learn that any person, at least in modern times, had ever seen it. Inquiries were made of nearly all the principal scientific bodies in Europe, and in several of the best continental libraries in vain. At last, by the assistance of Mr. Winter Jones, Principal Librarian of the British Museum, a copy was discovered in the library of the Museum. 600 copies have been taken in a reduced size, for insertion, as an Appendix, in the Magnetical and Meteorological volume for 1869 .

On the subject of Chronometers it is remarked, "The performance of chronometers, as depending on their mechanical construction, is very admirable; I have remarked but one point on which I could desire change, namely, that the balance should be struck more lightly, at a greater distance from its axis; the late Mr. Charles Frodsham, at my suggestion, had made experiments on this point, which promised to be successful. The principal errors of even moderately good chronometers are, however, produced by defective compensation, which the most skilful makers cannot perfectly manage. I have long been of opinion that the final adjustment for compensation ought to be made by some more delicate operation than that which suffices for approximate compensation; but the able chronometer-makers whom I have consulted have not yet devised a satisfactory plan."

With reference to Time Signals, we read that a proposal has been made to have a time-ball dropped at Queenstown, and that the report of the Westminster Clock shows that 55 per cent. of its errors are under $I^{\text {s }}$, and 94 per cent. under $3^{\text {s. }}$.

In December two attempts were made to determine the longitude of Gibraltar, at the request of Professor Newcomb, but without success, the cable connecting Falmouth and Gibraltar being out of order.

During the year the time of the Astronomer Royal has been partly occupied in preparations for the Transit of Venus, I874. Measures have been taken for equipping each of five stations with a Transit, an Altazimuth, and an Equatoreal. Some other instruments mounted in temporary observatories were inspected by the visitors. Of Transits there are five new, all mounted on stone piers. Of clocks to accompany them, there are two from the Royal Observatory, three new. Of Altazimuths, one from the Royal Observatory, four new. Of Equatoreals, 6 inches in aperture, and carried by clock-work, there are five, purchased or new. Of clocks of an inferior class, to accompany the two last classes of instruments, one can be supplied, nine must be procured. Fifteen portable observatories must be prepared, of which specimens were exhibited to the visitors. The Royal Observatory can supply three 4 -inch detached telescopes, and two more will be desirable.

The report goes on to say:-_" My preparations have respect only to eye-observation of contact of limbs. With all the liabilities and defects to which it is subject, this method possesses the inestimable advantage of placing no reliance on instrumental 
scales. I hope that the error of observation may not exceed four seconds of time, corresponding to about $0^{\prime \prime} \cdot 13$ of arc. I shall be very glad to see, in a detailed form, a plan for making the proper measures by heliometric or photographic apparatus; and should take great interest in combining these with the eye-observations, if my selected stations can be made available. But my present impression is one of doubt on the certainty of equality of parts in the scale employed. An error depending on this cause could not be diminished by any repetition of observations. As, in the event of any national enterprise being promoted in the direction of photographic record, it is probable that the Astronomer Royal may ministerially take an important part, I venture to submit to the Board of Visitors that suggestions on the value and plan of such observations fall entirely within their competence."

All the American observers of the Solar Eclipse, as well as $M$. Janssen, have visited the Observatory during the past year.

The current reductions of observations, it is remarked, are in a healthy state. Regular reductions give, "in general, great facility for the most advanced inferences; the star-catalogues, and solar, lunar, and planetary errors, lend themselves immediately to investigations of a physical character; the magnetic reauctions distinctly, though tacitly, exhibit some of those results (for instance, annual inequalities) which in various observatories have been the subject of special memoirs.

"But from time to time it becomes desirable to unite some of those annual or nearly annual results in groups, so as to exhibit the results jusily derivable from masses of observations extending over long periods of years. These operations require new organisations ; and, what is worse, they require additional granis of money. I have usually refrained from asking for these, without the distinct approval of the Visitors. I would now submit for their judoment the following subjects :-

"The vigorous prosecution of the Meteorological Reductions (exhibiting the results deducible from the photographic registers) already begun.

"The combination of the results of Magnetic Observations on disturbed days, from the year 1864 .

"The discussion of Magnetic Storms, from the year 1858 .

"Perhaps, also, the discussion of observations in groups depending on Lunar Declination, or other phases."

The report concludes as follows:-" There is another consideration which very often presents itself to my mind: the waste of labour in the repetition of observations at different observatories. The actual Greenwich system was established when there was little to compete with. Other obscrvatories have since arisen, equipped with and principally using the same classes of instruments, and devoting themselves in great measure to the samesubjects of observation (except the unrelenting pursuit of the moon, and perhaps the fundamental elements of the ecliptic). Ought this Observatory to retire from the competition? I think not; believing that there is greater security here than anywhere else for the unbroken continuity of system which gives the principal value to series of observations. Still, I remark that much labour is wasted, and that, on one side or another, that consideration ought not to be put out of sight in planning the courses of different observatories.'

This is a very broad hint for some English as well as Foreign Observatories, and it will be well for the cause of Science if the directors of those observatories will take it.

\section{THE SCIENTIFIC VALUE OF CHEESE- FACTORIES}

HE American system of cheese-factories was established nearly twenty years ago, and in its present condition of maturity it retains all the essential features which were characteristic of its infancy.* The test of twenty years' experience in a country where apparent improvements are eagerly submitted to a fair trial is amply sufficient to prove the success of the system. Recently the question of its adaptability to English dairy districts has acquired considerable prominence in agricultural circles, and is now passing from the stage of discussion to that of experiment. The two great merits which are claimed for it are, economy in the labour of production, and superiority of quality in the produce. It is evident that if a dozen farmers convey their milk to one building (a factory) to be made into cheese or butter, fewer hands are required to perform the work than if the process were carried on at a dozen different places by as many sets of people. The factory can be furnished with better laboursaving machinery than the farm-dairy, and the former establishment requires no more supervision than the latter. The process of cheese-making, also, occupies practically the same length of time, whether the quantity of milk under treatment be large or small, so that two or three persons whose energies are concentrated at one place will produce as great an economic result as a dozen or more who are necessarily employed at as many different points, each one going through the same routine independently of the other.

The superiority in the quality of the manufactured article may be more difficult of explanation, for the best farm-dairies produce as good cheese as any factory. The reason why the establishment of factories has improved the average make of cheese is because fewer first-rate cheese-makers are required under the factory system. But when Mr. Jesse Williams established the first factory twenty years ago, the great bulk of American cheese was extremely poor; and for many years after it was almost unsaleable in the English market. At the present day, on the contrary, it can compete on even terms with all but the very choicest English makes, notwithstanding that it has to undergo the ordeal of a long sea-voyage. The factory-system, therefore, has not only improved the average quality of American chcese, but it has very considerably raised the standard of the choicest brands.

Students of nature are perfectly well aware that the most sure and rapid progress is made by means of association and co-operation. The same phenomena are observed from different points of view by workers in the same field; a comparison of their notes leads to the grouping of kindred facts ; the apparent exceptions are seen to be the product of attendant variations in the methods or circumstances of observation ; and by a process of induction an explanatory theory is arrived at, to be confirmed or rejected by future investigations. In this manner the cheese-factory system has gone far towards the establishment in America of a science of cheese-making. Each factory has been the theatre of exact observations, which have been duly recorded. The results of comparisons of these records have been embodied in papers read before the American Dairymen's Association; and the conclusions of the authors have been frequently put to the crucial test of experiment.

The American Dairymen's Association is only a child of the Factory-system. It is organised on a plan similar to that of the British Association for the Advancement of Science, and like that institution, holds an Annual "Convention," at which papers are read and lectures are delivered. These contributions to the literature of dairying, and the discussions thereon, are published in an annual "Report," which also contains detailed reports from numerous cheese and butter factories, giving the dates of commencing and finishing work, the number of cows supplying the factory, the quantity of milk received, the quantity of cheese made, the percentage of cheese to milk at different periods of the year, and as compared with

* For detailed descriptions of this system, vide Journal Royal Agricultural Society, and Series, vol. vi. p. I73, and vol. vii. p. $\bar{x}$. 